\title{
Comparative pharmacoeconomic assessment of apixaban vs. standard of care for the prevention of stroke in Italian atrial fibrillation patients
}

\author{
Lorenzo Pradelli ${ }^{1}$, Mario Calandriello ${ }^{2}$, Roberto Di Virgilio ${ }^{3}$, Marco Bellone ${ }^{1}$, \\ Marco Tubaro ${ }^{4}$ \\ AdRes, Health Economics \& Outcome Research, Turin, Italy \\ Bristol-Myers Squibb Italy, Rome, Italy \\ Pfizer Italy, Rome, Italy \\ ${ }^{4}$ ICCU, Cardiovascular Department, San Filippo Neri Hospital, Rome, Italy
}

\section{ABSTRACT}

OBJECTIVES: The aim of this study was to evaluate the cost-effectiveness of apixaban in the prevention of thromboembolic events in patients with non-valvular atrial fibrillation (NVAF) relatively to standard of care (warfarin or aspirin) from the Italian National Health System (SSN) perspective.

METHODS: A previously published lifetime Markov model was adapted for Italian context. Clinical effectiveness data were acquired from head-to-head randomized trials (ARISTOTLE and AVERROES); main events considered in the model were ischemic and hemorrhagic stroke, systemic thromboembolism, bleeds (both major and clinically relevant minor) and cardiovascular hospitalizations, besides treatment discontinuations. Expected survival was projected beyond trial duration using national mortality data adjusted for individual clinical risks and adjusted by utility weights for health states acquired from literature. Unit costs were collected from published Italian sources and actualized to 2013. Costs and health gains accruing after the first year were discounted at an annual $3.5 \%$ rate. The primary outcome measure of the economic evaluation was the incremental cost effectiveness ratio (ICER), where effectiveness is measured in terms of life-years and quality adjusted life-years gained. Deterministic and probabilistic sensitivity analyses (PSA) were carried out to assess the effect of input uncertainty.

RESULTS: Apixaban is expected to reduce the incidence of ischemic events relative to aspirin and to improve bleeding safety profile when compared to warfarin. Incremental LYs $(0.31 / 0.19)$, QALYs $(0.28 / 0.20)$, and costs $(1,932 / 1,104)$ are predicted with the use of apixaban relative to aspirin and warfarin, respectively. The ICERs of apixaban were $€$ 6,794 and $€$ 5,607 per QALY gained, respectively. In PSA, the probability of apixaban being cost effective relative to aspirin and warfarin was $95 \%$ and $93 \%$, respectively, for a WTP threshold of $€ 20,000$ per QALY gained. Univariate analyses indicate that results were most sensitive to variations of the absolute risk reduction for cardiovascular events with apixaban.

CONCLUSIONS: Apixaban is expected to increase life expectancy and quality-adjusted life expectancy, but also costs dedicated to Italian NVAF patients, as compared to standard of care. The resulting ICERs have high probabilities of being below the conventional thresholds of WTP for health benefits of the SSN, indicating efficient allocation of health care resources.
\end{abstract}

\section{Keywords}

Apixaban; Novel oral anticoagulant agents; Atrial fibrillation

\section{INTRODUCTION}

Atrial fibrillation (AF) is the most prevalent form of arrhythmia, involving about $1-2 \%$ of the population in industrialized countries [1]. Its prevalence increases with age, reaching values above $5 \%$ in the over 65 years old, and of $9 \%$ in octogenarians [2].
In Italy, a prevalence of $600,000 \mathrm{AF}$ patients was estimated for year 2010, and a further increase is expected due to the increasing age of the population and the improved survival of cardiovascular patients [3]. Stroke is the main complication of $\mathrm{AF}$ [4]: over $20 \%$ of ischemic strokes are linked to some
Corresponding author Lorenzo Pradelli

I.pradelli@adreshe.com

\section{Disclosure}

Study funded by

Bristol-Myers Squibb

and Pfizer 


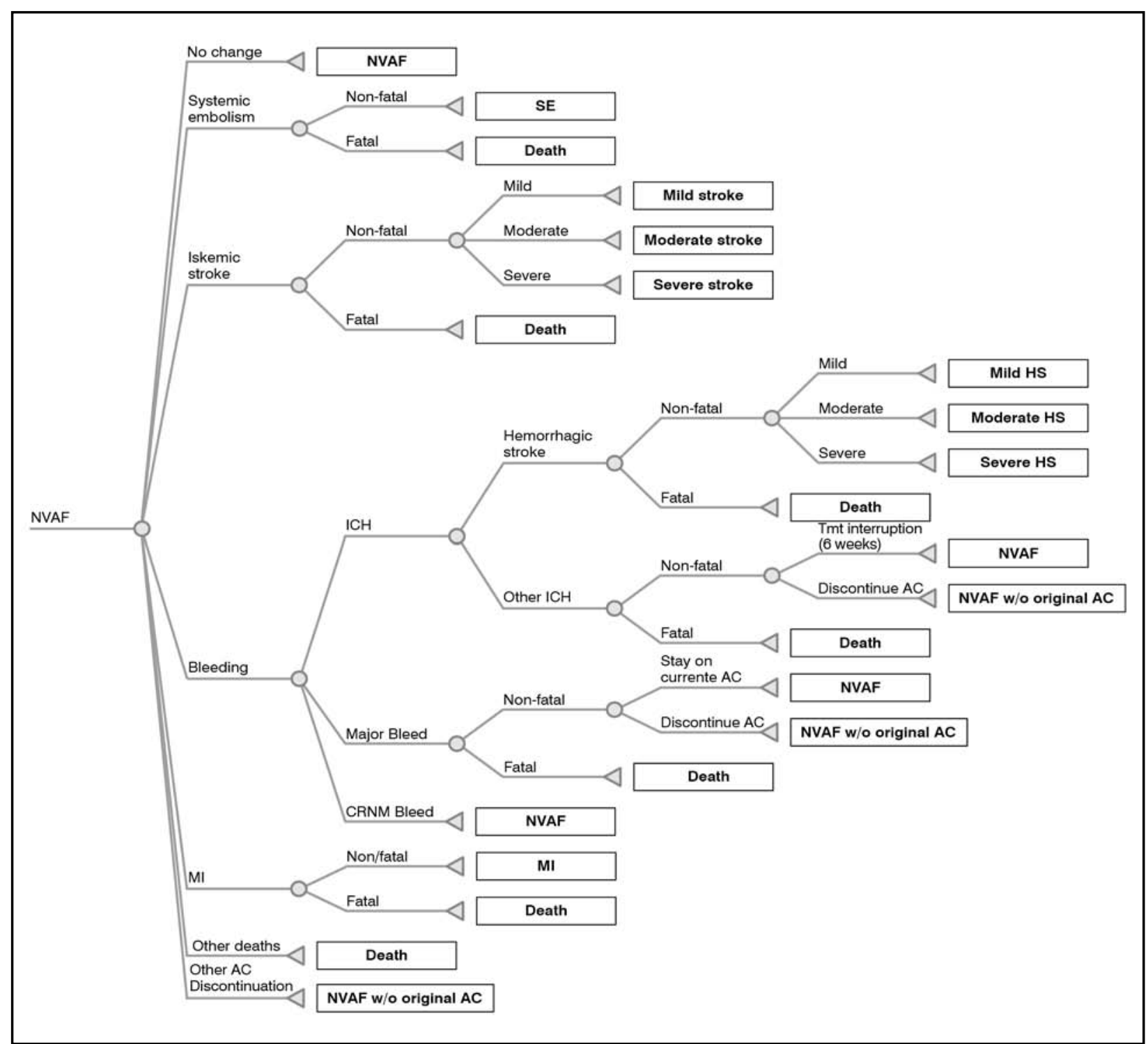

Figure 1. Simplified structure of the Markov model

form of arrhythmia [1], and in these patients, they tend to be more severe than in non-arrhythmic patients [5]. About $40 \%$ of stroke survivors presents moderate to severe disability; applying these rates to the prevalent population, it has been calculated that around 384,000 are not autonomous in Italy due to stroke, and this figure is expected to rise up to 440,000 by 2020 [6].

Therapeutic goals in the management of AF patients include symptom control, but also the prevention of thromboembolic complications, stroke in primis. This was traditionally pursued with the administration of vitamin $\mathrm{K}$ antagonists (VKA), or with antiplatelet agents, mainly aspirin, in subjects intolerant or contraindicated to VKAs [7].

Apixaban, a direct and selective coagulation factor Xa inhibitor, which is associated with a more favorable risk/benefit ratio than VKA and aspirin [8,9] is facing the launch on the market for the thromboembolic prevention in non-valvular AF (NVAF, about $70 \%$ of all FA cases), with reimbursement restrictions: NVAF with both $\mathrm{CHA}_{2} \mathrm{DS}_{2}-\mathrm{VASc} \geq 1^{1}$ and HAS-BLED $>3^{2}$, or TTR $<70 \%$ or objective difficulties in measuring INR [10].

The objective of the present analysis is the evaluation of the cost/effectiveness of the use of apixaban in the prevention of thromboem-

Calculates stroke risk for patients with atrial fibrillation, possibly better than the $\mathrm{CHADS}_{2}$ score. It is composed of 7 domains: Age (1 point for ages 65-74, 2 points for $>74$ ); Gender (Female, 1 point); Congestive Heart Failure History (Yes, 1 point); Hypertension History (Yes, 1 point); Stroke/ TIA/Thromboembolism History (Yes, 2 points), Vascular Disease History (Yes, 1 point), and Diabetes Mellitus (Yes, 1 point)

2 "HAS-BLED" is an acronym for: Hypertension, Abnormal Liver/Renal Function, Stroke History, Bleeding Predisposition, Labile INR, "Elderly" (Age > 65), Drugs/Alcohol Usage, with each of the domains scored 1 point if present, to be added up to obtain total score, which correlates with the risk of major bleeding. Estimates risk of major bleeding for patients on anticoagulation to assess risk-benefit in atrial fibrillation care. 
bolic events in the indicated Italian population of patients with NVAF, as compared with the standard of care (warfarin for the suitable population, aspirin for the remaining).

\section{METHODS}

The analysis is conducted as a simulation study, performed through the adaptation of a previously published international model $[11,12]$ simulated using epidemiological, clinical practice and unit costs pertinent to the Italian setting. The model is designed to reproduce the experience of a cohort of NVAF patients of user defined features, alternatively treated with the compared therapeutic options. During the lifetime simulation, events and consumed resources from the Italian National Health System perspective are recorded by the model; main clinical outcomes monitored are ischemic and hemorrhagic stroke, systemic thromboembolism, bleeds (both major and clinically relevant minor), cardiovascular hospitalizations, and death. Summary effectiveness indicators are overall survival, expressed in life years (LY), and expected quality-adjusted survival, expressed in quality-adjusted life years (QALYs).

\section{Model structure}

The model is designed as a decision tree with Markov chains as branches; the experience of a NVAF patient is discretized in 17 possible and mutually exclusive health states (Figure 1). Transitions among health states are determined by probability matrices derived from the relevant literature as detailed elsewhere [11].

At the end of each 6 week cycle, patients can stay in the current health state, or experience a clinical event and transition to the corresponding state; some events only imply a resource consumption and a temporary change in the utility (quality of life index), whilst others - i.e. stroke, myocardial infarction (MI), and systemic embolism - also modify the chance of incurring in further events. Stroke survivors distribute among subsequent health states basing on the assigned severity distribution of the specific event. Following a major bleeding, patients may continue to receive the initial anticoagulant, or switch to a second line treatment, associated with specific clinical event risks.

\section{Population}

The simulation is run on two cohorts (Table I): the first (base-case) reproducing clinical and demographic features of the AVERROES [9] and ARISTOTLE [8] trial population, for the

\begin{tabular}{lccc}
\hline & $\begin{array}{c}\text { Base-case - } \\
\text { VKA unsuitable } \\
\text { population [9] }\end{array}$ & $\begin{array}{c}\text { Base-case - } \\
\text { VKA suitable } \\
\text { population [8] }\end{array}$ & $\begin{array}{c}\text { Real-world } \\
\text { population } \\
\text { [13] }\end{array}$ \\
\hline \% males & 59 & 65 & 53 \\
Mean age (years) & 70 & 70 & 77 \\
CHADS, score (\%) & & & \\
0-1 & 38 & 34 & 53 \\
2 & 35 & 36 & 23 \\
$>2$ & 27 & 30 & 24 \\
\hline
\end{tabular}

Table I. Baseline characteristics of the simulated populations: base-case patient populations, from AVERROES [9] and ARISTOTLE [8] trials, and alternative-case population, from a nationwide cohort of real world patients, registered in the Danish patient registry [13]

analysis of NVAF patients unsuitable and suitable for VKA therapy, respectively; the second those of a non-experimental population of NVAF patients studied by Olesen et al. [13]. In this cohort study, Olesen et al. assessed the individual risk factors composing the $\mathrm{CHADS}_{2}$ and $\mathrm{CHA}_{2} \mathrm{DS}_{2}$-VASc score calculating the capability of the schemes to predict thromboembolism in a nationwide cohort of Danish real world patients.

\section{Clinical outcomes rates}

The effectiveness and safety profile of apixaban by VKA suitability reflects event rates recorded in the ARISTOTLE [8] and AVERROES trials [9], integrated with patient-level data made available by Dorian et al. (Table II). ARISTOTLE was an international, multicentre, double-blind, double-dummy, placebo-controlled, randomised controlled trial that compared apixaban with warfarin in 18,201 adults with atrial fibrillation and at least one additional risk factor for stroke, assessed by $\mathrm{CHADS}_{2}$ criteria. Apixaban was associated with a significantly lower rate of stroke and systemic embolism than warfarin. When strokes were analysed separately, apixaban was associated with a significant reduction in hemorrhagic stroke compared with warfarin. Episodes of fatal or disabling stroke were significantly lower in the apixaban arm. The safety analyses point out as apixaban resulted in significantly fewer bleeding events than warfarin for all of the major bleed types and clinically relevant non-major bleeding events.

AVERROES study was an international, multicentre, double-blind, double-dummy, placebo-controlled, randomised controlled trial that compared apixaban with aspirin in 5,599 adults with atrial fibrillation and at least 1 additional risk factor for stroke for whom treatment with warfarin was unsuitable or the patients were unwilling to take it. Apixaban reduced the rate of stroke and 
systemic embolism compared with aspirin; rates of fatal or disabling stroke were also lower in patients who received apixaban. When strokes were considered as a separate outcome, apixaban decreased the rates of ischaemic stroke compared with aspirin but did not statistically significantly decrease the rates of hemorrhagic stroke.

Increasing age is associated with higher ischemic stroke (IS) risk; in the model, this is accounted for by applying a HR of 1.4 per decade [14]. Severity distribution of ISs is classified according to the modified Rankin scale (mRS - mild 0-2; moderate 3-4; severe 5 and fatal 6) specific to the anticoagulant (AC) treatment and was derived from published literature (Table II).

Similarly, the model accounts for age-related increase in Intra Cranial Hemorrhages (ICH) risk by applying a $1.97 \mathrm{HR}$ per decade [15].
Hemorrhagic strokes (HS) are determined as a treatment-specific percentage of ICHs; similarly, their severity distribution, again expressed in terms of mRS, is treatment-specific.

IS and HS survivors are at risk of recurrence: this is modelled according to a real-life registry indicating a cumulative incidence of 4.1 and 3.0 per 100 patient-years, respectively [16]; the severity distribution of recurrent strokes is conditional on the severity of the first stroke, as observed in ARISTOTLE and AVERROES.

As with IS and ICH, the model accounts for increasing MI risk with higher ages by applying an HR of 1.30 per decade [17]. MI case fatality rates applied in the simulation are specific for gender $(10.8 \%$ in men and 15.6 for women), differently than for SE $(9.4 \%)$ [18].

\begin{tabular}{|c|c|c|c|c|c|}
\hline & \multicolumn{2}{|c|}{ VKA suitable } & \multicolumn{2}{|c|}{ VKA unsuitable } & \multirow{2}{*}{$\begin{array}{c}\text { Second line therapy } \\
\left.\text { ASA ( } 2^{\text {nd }} \text { line }\right)\end{array}$} \\
\hline & Apixaban & Warfarin & Apixaban & ASA & \\
\hline IS* (Rate/100 pts-yr) & 0.98 & 1.08 & 1.37 & 3.10 & $3.45^{5}$ \\
\hline \multicolumn{6}{|l|}{ Pts distribution (\%) } \\
\hline • Mild mRS (0-2) & 53 & 45 & 40 & 36 & $36^{4}$ \\
\hline - Moderate mRS (3-4) & 21 & 30 & 28 & 38 & $38^{4}$ \\
\hline - Severe mRS (5) & 8 & 10 & 12 & 15 & $15^{4}$ \\
\hline • Fatal mRS (6) & 18 & 15 & 20 & 11 & $11^{4}$ \\
\hline ICH* (Rate/100 pts-yr) & 0.33 & 0.80 & 0,34 & 0,35 & $0.32^{5}$ \\
\hline Other ICH (\%) & 23 & 36 & 45 & 45 & $45^{4}$ \\
\hline Case Fatality Rates (\%) & $13^{2}$ & $13^{2}$ & $13^{2}$ & $13^{2}$ & $13^{4}$ \\
\hline Proportion of HS (\%) & 77 & 64 & 55 & 55 & $55^{4}$ \\
\hline • Mild mRS (0-2) & 23 & 20 & 7 & 7 & $7^{4}$ \\
\hline - Moderate mRS (3-4) & 32 & 15 & 20 & 20 & $20^{4}$ \\
\hline - Severe mRS (5) & 10 & 12 & 27 & 27 & $27^{4}$ \\
\hline • Fatal mRS (6) & 35 & 53 & 46 & 46 & $46^{4}$ \\
\hline Other MB* (Rate/100 pts-yr) & 1.79 & 2.27 & 1,07 & 0,57 & $0.89^{5}$ \\
\hline Case Fatality Rates (\%) & $2^{2}$ & $2^{2}$ & $2^{2}$ & $2^{2}$ & $2^{4}$ \\
\hline Proportion of GI Bleeds (\%) & 38 & 35 & 35 & 39 & $39^{4}$ \\
\hline CRNM (Rate/100 pts-yr) & 2.08 & 2.99 & 3.11 & 2.37 & $2.94^{5}$ \\
\hline MI* (Rate/100 pts-yr) & 0.53 & 0.61 & 0.76 & 0.89 & $1.11^{5}$ \\
\hline SE (Rate/100 pts-yr) & 0.09 & 0.10 & 0.0 & 0.41 & $0.40^{3}$ \\
\hline Other CV Hosp (Rate/100 pts-yr) & $10.46^{2}$ & $10.46^{1}$ & 10.46 & 12.09 & $13.57^{5}$ \\
\hline Other Treat Disc (Rate/100 pts-yr) & 13.18 & 14.41 & 17.31 & 19.01 & - \\
\hline Background mortality ${ }^{\circ}$ (Rate/100 pts-yr) & 3.08 & 3.34 & 2.97 & 3.59 & - \\
\hline
\end{tabular}

Table II - Summary of main clinical inputs used in the analysis [11]

CRNM: Clinically Relevant non Major Bleeds; Gl: Gastrolntestinal Bleeds; HS: Hemorrhagic Stroke; ICH: IntraCranial Hemorrhages; IS: Ischemic

Stroke; MI: Myocardial Infarction; Other CV Hosp: Other CardioVascular Hospitalization; Other MB: Other Major Bleeds; Other TreatDisc: Other

Treatment Discontinuation; pts: Patients; SE: Systemic Embolism; yr: year

${ }^{1}$ Assumption (same rate as the apixaban's rate observed among the VKA unsuitable population):

2 Pooled sample percentages;

${ }^{3}$ Assumption (same rate as ASA first line observed in the VKA unsuitable population)

${ }^{4}$ Assumption (same distribution as ASA first line)

${ }^{5}$ Subgroup of patients who had VKA-unsuitability "demonstrated" (i.e., previously failed warfarin)

* Stroke, bleeds and MI risks are adjusted over time to take into account the increased risks with aging: HR for adjunctive decade of 1.4 [14], 1.97

[15], and 1.3 [17], respectively, are applied

${ }^{\circ}$ For the duration of the trial period (1.9 years (ARISTOTLE) and 1.2 years (AVERROES)) 


\begin{tabular}{ccccc|cccc}
\hline \multirow{2}{*}{$\begin{array}{c}\text { Health } \\
\text { condition }\end{array}$} & \multirow{2}{*}{ NVAF [20] } & \multicolumn{3}{c}{ Stroke [21-23] } & \multicolumn{3}{c}{ MI [24] } & SE $^{\circ}$ \\
\cline { 3 - 9 } & & Mild & Moderate & Severe & Female & Male & \\
\hline HR & 1.34 & 3.18 & 5.84 & 15.75 & 4.16 & 2.56 & 1.34 \\
\hline
\end{tabular}

Table III. Death hazard ratios according to the health condition of the simulated patient

-Assumption

During the simulation, patients may discontinue treatment, either completely, or by switching to another $\mathrm{AC}$ regimen, as a consequence of clinical events incurred, or for other reasons, as described on Dorian et al. [11] and Lip et al. [12].

Besides the already described case fatality rates for stroke, bleeding, and MI, the population is subjected to a background mortality derived from ARISTOTLE for the duration of the trial follow-up; given the lack of sound comparative mortality rates, the same background mortality has been applied to all NOACs.

Beyond the trial duration, mortality is projected based on Gompertz distributions fitted on Italian age- and gender-specific population rates [19], corrected for the HRs associated to $\mathrm{AF}, \mathrm{MI}$, stroke, and SE, as shown in Table III.

\section{Utility}

Baseline utility assigned to the simulated population derives from a preference study conducted on AF patients [25]. The model accounts for reduced preference for warfarin and ASA administration, as reported in Gage et al. [26]; temporary disutilities are assigned to patients experiencing clinical events, as shown in Table IV.

\section{Costs}

Costs are evaluated from the perspective of the National Health System (SSN); accordingly, only direct health care costs are considered:

- Drug acquisition costs, at negotiated net prices [27] (Table V);

- Routine visits [28] for all treated patients and INR monitoring for warfarin treated patients, basing on data reported by Pengo in 2011 [29] and Mennini in 2012 [30];

- Acute event management (strokes, bleeds, myocardial infarction, and other CV hospitalizations);

- Long-term post-event management for stroke, MI, and SE;

- Other health care costs associated with AC management (Table VI).

Stroke management costs have been elaborated basing on data reported in an observational study conducted on 411 Italian stroke survivors, followed up for 12 months [31]:

\begin{tabular}{|c|c|c|}
\hline Condition & Mean utility & Disutility (duration) \\
\hline Atrial fibrillation (Baseline) & $0.7270[25]$ & \\
\hline \multicolumn{3}{|l|}{ Ischemic stroke } \\
\hline Mild & $0.6151[25]$ & \\
\hline Moderate & $0.5646[25]$ & \\
\hline Severe & $0.5142[25]$ & \\
\hline \multicolumn{3}{|l|}{ Hemorrhagic stroke } \\
\hline Mild & $0.6151[25]$ & \\
\hline Moderate & $0.5646[25]$ & \\
\hline Severe & $0.5142[25]$ & \\
\hline Myocardial infarction & $0.6098[25]$ & \\
\hline Systemic embolism & 0.6265 [25] & \\
\hline $\begin{array}{l}\text { Other intracranial } \\
\text { hemorrhages }\end{array}$ & & $-0.1511[25](6$ weeks $[11,12])$ \\
\hline Other major bleeding & & -0.1511 [25] (14 days)* \\
\hline $\begin{array}{l}\text { Clinical relevant, } \\
\text { non major bleeds }\end{array}$ & & $-0.0582[25](2$ days)* \\
\hline Other CV hospitalizations & & $-0.1276[25]$ (6 days $[11,12])$ \\
\hline \multicolumn{3}{|l|}{ Drug utilization } \\
\hline Aspirin & & $-0.0020[26]$ \\
\hline Warfarin & & $-0.0120[26]$ \\
\hline
\end{tabular}

Table IV. Utilities and disutilities used in the simulation

* Assumption based on Freeman, 2011 [17] and reported on Dorian, 2014 [11] and Lip, 2014 [12]

\begin{tabular}{lcc}
\hline \multicolumn{1}{c}{ Drug } & Dose $(\mathbf{m g} /$ die) & Daily cost (€) \\
\hline Aspirin & 100 & 0.04 \\
Warfarin & 5 & 0.03 \\
Apixaban & 10 & 1.90 \\
\hline
\end{tabular}

Table V. Drug acquisition costs, at negotiated net prices [27]

for each severity category within ischemic and hemorrhagic strokes, the mean long-term maintenance cost has been approximated to the monthly cost recorded in the second semester; the costs for the acute phase correspond to the sum of the corresponding DRG tariff [32] and the difference between the costs accrued in the first and second follow-up semester.

For acute and long-term MI management, cost data are elaborated basing on three-year follow-up data reported for Italian MI survivors [33]. The costs attributed to the other clinical events considered are equaled to the 


\begin{tabular}{|c|c|c|c|c|}
\hline & Unit cost $(€)$ & Unit & Duration & Source \\
\hline INR monitoring & 380 & per year & $\mathrm{N} / \mathrm{A}$ & Mennini et al. [30] \\
\hline Routine visit & 15.37 & per visit & $\mathrm{N} / \mathrm{A}$ & Lucioni et al. [28] \\
\hline \multicolumn{5}{|l|}{ Ischemic Stroke } \\
\hline \multicolumn{5}{|l|}{ Mild } \\
\hline - Acute & $4,663.06$ & per episode & 2 weeks & Fattore et al. [31] \\
\hline - Maintenance & 81.76 & per month & Lifetime & Fattore et al. [31] \\
\hline \multicolumn{5}{|l|}{ Moderate } \\
\hline - Acute & $6,137.96$ & per episode & 2 weeks & Fattore et al. [31] \\
\hline - Maintenance & 139.04 & per month & Lifetime & Fattore et al. [31] \\
\hline \multicolumn{5}{|l|}{ Severe } \\
\hline - Acute & $10,311.34$ & per episode & 2 weeks & Fattore et al. [31] \\
\hline - Maintenance & 327.95 & per month & Lifetime & Fattore et al. [31] \\
\hline Fatal & $3,891.00$ & per episode & N/A & DRG 14 [32] \\
\hline \multicolumn{5}{|l|}{ Hemorrhagic stroke } \\
\hline \multicolumn{5}{|l|}{ Mild } \\
\hline - Acute & $6,321.14$ & per episode & 2 weeks & Fattore et al. [31] \\
\hline - Maintenance & 118.11 & per month & Lifetime & Fattore et al. [31] \\
\hline \multicolumn{5}{|l|}{ Moderate } \\
\hline - Acute & $10,073.43$ & per episode & 2 weeks & Fattore et al. [31] \\
\hline - Maintenance & 200.86 & per month & Lifetime & Fattore et al. [31] \\
\hline \multicolumn{5}{|l|}{ Severe } \\
\hline - Acute & $20,932.42$ & per episode & 2 weeks & Fattore et al. [31] \\
\hline - Maintenance & 473.77 & per month & Lifetime & Fattore et al. [31] \\
\hline Fatal & 3,891 & per episode & N/A & DRG 14 [32] \\
\hline Other ICH & 25,812 & per month & N/A & DRG 528 [32] \\
\hline Other major bleeding & 3,317 & per episode & N/A & DRG 174 [32] \\
\hline CRNMB & 2,091 & per episode & $\mathrm{N} / \mathrm{A}$ & DRG 175 [32] \\
\hline \multicolumn{5}{|l|}{ IM } \\
\hline - Acute & $6,275.21$ & per episode & $\mathrm{N} / \mathrm{A}$ & Mantovani et al. [33] \\
\hline - Maintenance & 157.97 & per month & Lifetime & Mantovani et al. [33] \\
\hline \multicolumn{5}{|l|}{ SE } \\
\hline - Acute & $4,663.06$ & per episode & 2 weeks & Assumption \\
\hline - Maintenance & 81.76 & per month & Lifetime & Assumption \\
\hline Other CV hospitalization & 4,742 & per episode & N/A & DRG 479 [32] \\
\hline
\end{tabular}

Table VI. Cost inputs

corresponding DRG-based tariff [32] paid to the hospitals by the SSN.

Other AC related costs considered are related to dyspepsia management ( $€ 71.46 /$ year [34], rates of dyspepsia from ARISTOTLE for apixaban and warfarin).

All historical cost data have been actualized to 2013 values using official indices [19].

\section{Incremental cost/ effectiveness analysis}

Lifetime results from the simulation are presented as incremental cost/effectiveness and incremental cost/utility ratios, i.e. as the ratio of the difference in costs over the difference in life years and quality-adjusted life years, respectively.
The effect of parameter uncertainty on the results is assessed by probabilistic sensitivity analyses (PSA), in which the model is re-evaluated with 2000 sets of parameter values sampled from appropriate distributions. The influence of single parameters on the results is evaluated with a series of one-way deterministic sensitivity analyses (DSA), in which the model is re-calculated using extreme parameter values, corresponding to the lower and upper limits of the $95 \%$ confidence interval; when this was unavailable from the original data, it has been calculated assuming a SEM equaling $25 \%$ of the mean.

In incremental cost/effectiveness analyses, costs and benefits accruing after the first year are discounted at a $3.5 \%$ annual rate. 


\section{RESULTS}

In Table VII, the expected clinical events accruing in two hypothetical populations of NVAF patients over lifetime are presented. According to the clinical trials' results, apixaban is expected to reduce the incidence of ischemic events when compared to aspirin. In the comparison against warfarin in the relevant population, apixaban is associated with an estimated improved bleeding safety profile. When converted into the summary indicators (Table VIII) used for the incremental allocation

\begin{tabular}{lcc|cc}
\hline \multirow{2}{*}{ Events on total population (n.) } & \multicolumn{2}{c}{ VKA unsuitable } & \multicolumn{2}{c}{ VKA suitable } \\
\cline { 2 - 5 } & Apixaban & Aspirin & Apixaban & Warfarin \\
\hline Ischemic Stroke & 268 & 317 & 238 & 241 \\
Recurrent Ischemic Stroke & 33 & 44 & 29 & 30 \\
Hemorrhagic Stroke & 21 & 19 & 27 & 41 \\
Recurrent Hemorrhagic Stroke & 1 & 1 & 2 & 2 \\
Systemic Embolism & 26 & 37 & 26 & 26 \\
Other ICH & 17 & 15 & 13 & 25 \\
Other Major Bleeds & 111 & 76 & 298 & 187 \\
Clinically Relevant Non-Major Bleeds & 344 & 273 & 88 & 341 \\
MI & 100 & 97 & 1,231 & 90 \\
Other CV Hospitalization & 1,231 & 1,189 & 645 & 1,200 \\
Other Treatment Discontinuation & 709 & 675 & & 641 \\
\hline
\end{tabular}

Table VII. Clinical events among 1,000 VKA unsuitable and VKA suitable patients over lifetime

\begin{tabular}{lccccc}
\hline & Lifetime result & & $\begin{array}{c}\text { Delta } \\
\text { (apixaban - }\end{array}$ & $\begin{array}{c}\text { ICER } \\
\text { comparator) }\end{array}$ & $\begin{array}{c}\text { (apixaban vs. } \\
\text { comparator) }\end{array}$ \\
\cline { 2 - 5 } & Apixaban & Apixaban & ASA & & \\
VKA suitable & 14,133 & 13,029 & & 1,104 & 5,607 \\
Total cost (€) & 6.48 & 6.28 & & 0.20 & 5,814 \\
QALY & 9.12 & 8.93 & & 0.19 & \\
LY & 14,215 & & 12,283 & 1,932 & 6,794 \\
VKA unsuitable & 6.45 & & 6.17 & 0.28 & 6,177 \\
Total cost (€) & 9.10 & & 8.79 & 0.31 & \\
QALY & & & & \\
LY & & & & & \\
\hline
\end{tabular}

Table VIII. Base-case CEA: accrued LYS, QALYs, total costs, and corresponding ICERs

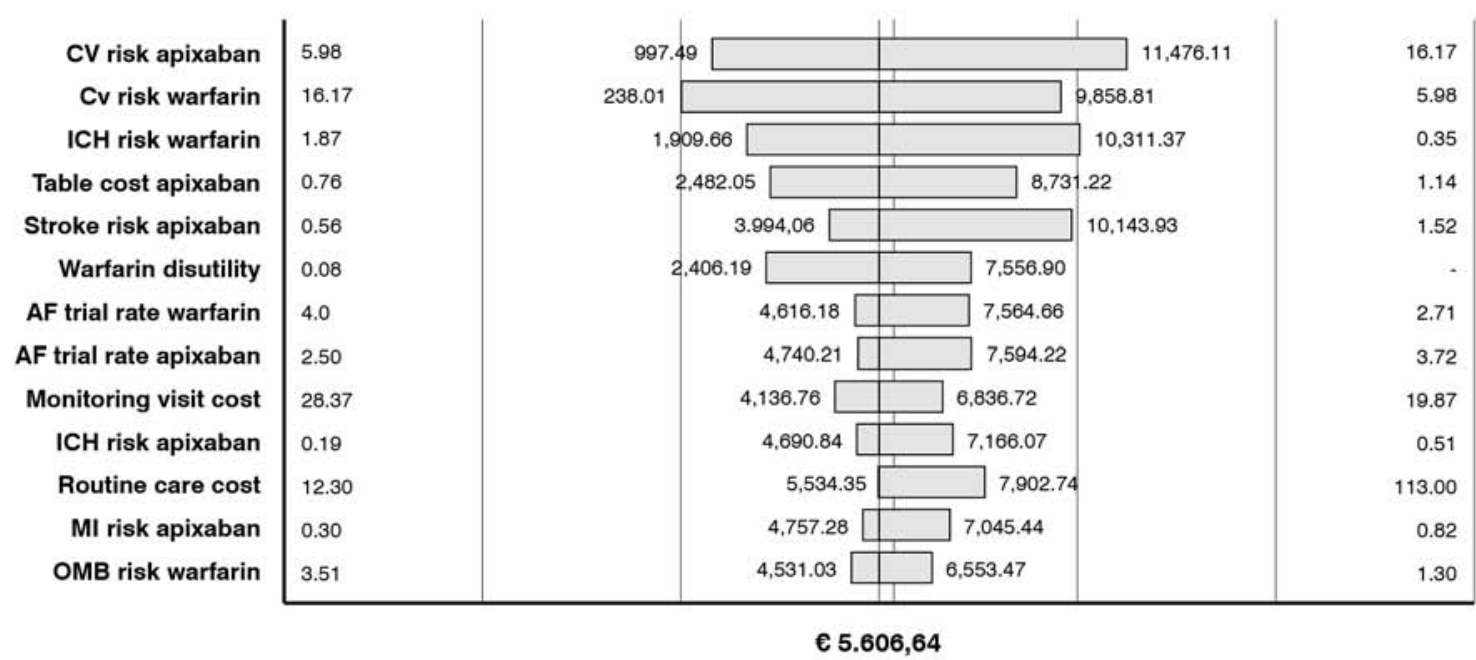

Figure 2. DSA apixaban vs. warfarin. The extreme values tested for each parameter are reported on the same line of the corresponding bar 


\begin{tabular}{r|l} 
Stroke risk aspirin & 4.44 \\
CV risk apixaban & 5.98 \\
Stroke risk apixaban & 0.79 \\
Tablet cost apixaban & 0.76 \\
ICH risk aspirin & 1.04 \\
MI risk aspirin & 1.52 \\
MI risk apixaban & 0.43 \\
CV risk aspirin & 14.07 \\
ICH risk apixaban & 0.20 \\
Stroke risk adjustment & 2.16 \\
Routine care cost & 12.30 \\
TMT disc risk apixaban & 26.77 \\
Male age & 63.00
\end{tabular}

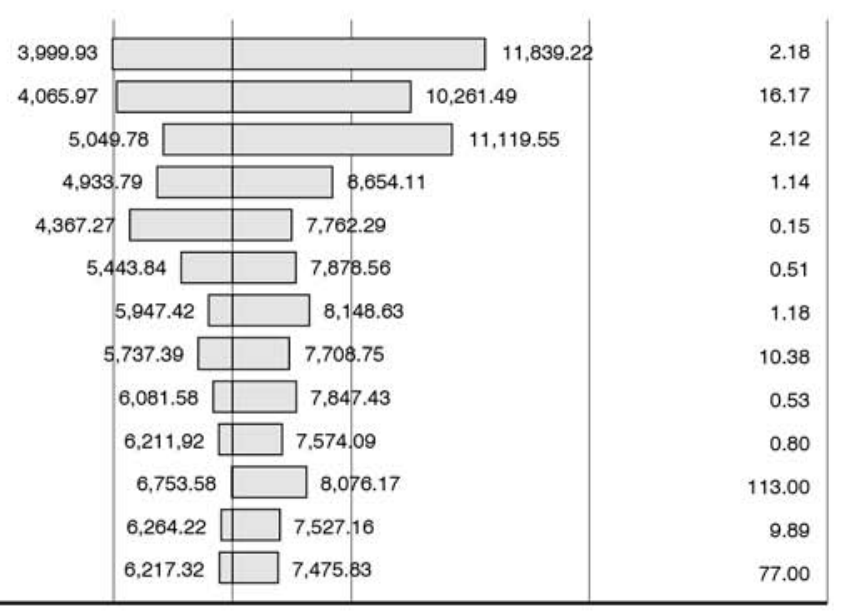

6 6,793.95

Figure 3. DSA apixaban vs. ASA. The extreme values tested for each parameter are reported on the same line of the corresponding bar

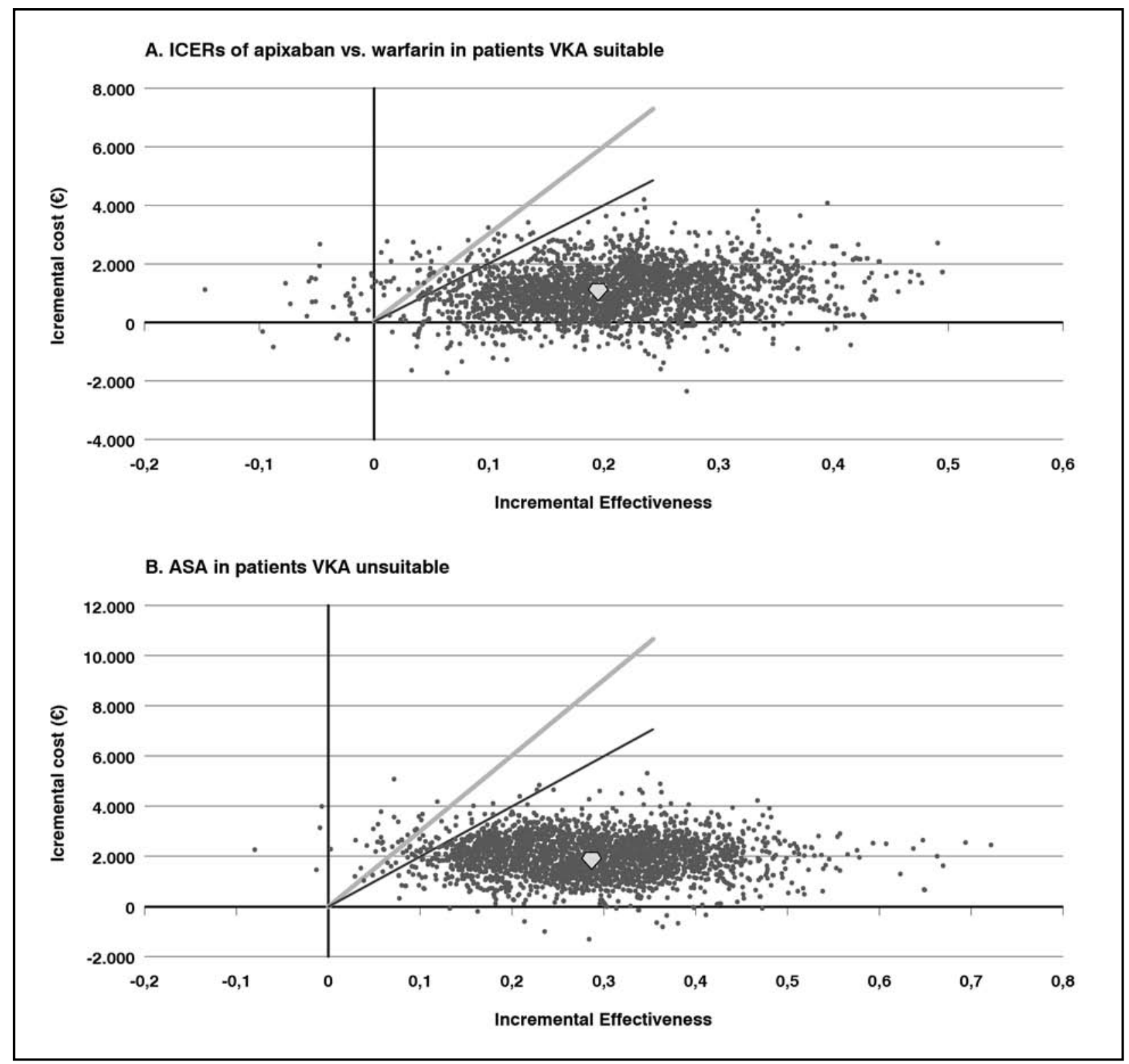

Figure 4. PSA: scatterplots of ICERs of apixaban vs. warfarin in patients VKA suitable (panel A) and ASA in patients VKA unsuitable (panel $B$ ). The two lines represent WTP thresholds: 20,000 and 30,000 €/QALY gained (lower and upper, respectively). The diamonds indicate the base case ICER 
efficiency analyses, the above figures translate into a gain of $0.19 \mathrm{LYs}$, or 0.20 QALYs, and of $0.31 \mathrm{LYs}$, or $0.27 \mathrm{QAYs}$, in the comparison against aspirin and warfarin, respectively. This improvement comes at an increased cost, which however, seems moderate, equaling around $€ 1,000$ and 2,000 per patient over a lifetime, respectively. In terms of incremental cost/effectiveness, this corresponds to 5,600 $€ /$ QALY or $5,800 € /$ LY gained and $€ 6,800 /$ QALY or $€ 6,200 /$ LY gained, respectively.

These ICERs indicate a favourable pharmacoeconomic profile, when assessed in terms of the willingness to pay for health benefits of the SSN, or of any other third party payer in industrialized countries.

DSA for the analysis of apixaban vs. warfarin is represented as a tornado diagram in Figure 2, showing the impact of single parameters on the estimated ICERs in order of decreasing magnitude of effect. The most influential parameters are the absolute $\mathrm{CV}$ risks for both treatments and the ICH risk associated with warfarin use; in any tested case, the corresponding ICER remains below commonly accepted WTP values.

The same considerations hold true for the comparison against ASA, where ICER is most influenced by variations of the attributed stroke risks for both treatments, and by the level of CV risk for apixaban-treated patients (Figure 3).

Probabilistic sensitivity analysis substantially confirms the findings of the main analysis, as shown in Figure 4 representing the distribution of the 2000 ICER estimates of the PSA. Apixaban is expected to be a better choice than warfarin for any WTP above about $10,000 € /$ QALY gained, with probabilities of being cost-effective of $93 \%$ and $96 \%$, for the conventional WTP thresholds of 20,000 and $30,000 € /$ QALY gained, respectively. Cor-

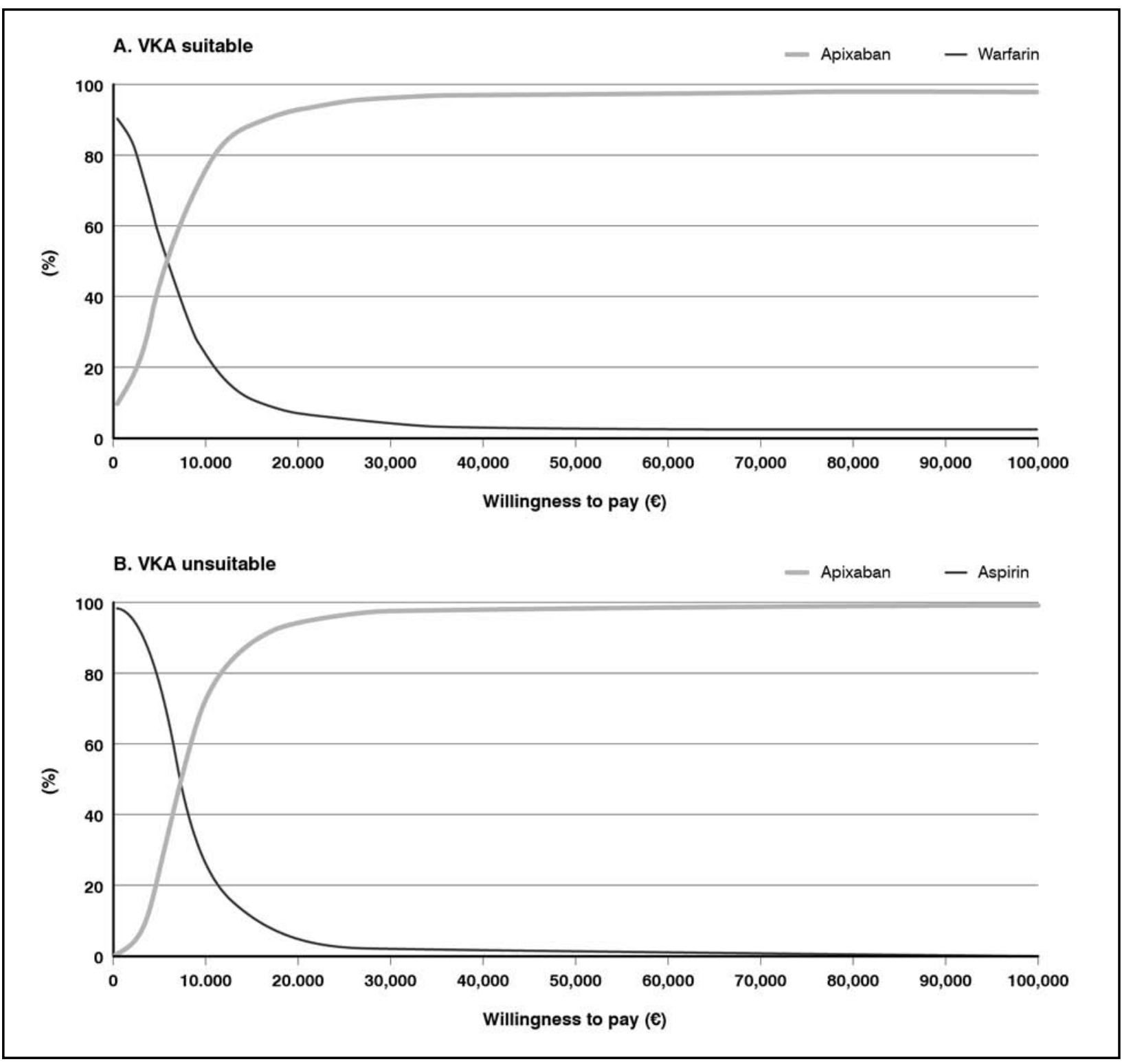

Figure 5. Probability of being the most cost-effective treatment choice in VKA suitable (panel A) and VKA unsuitable (panel B) patients 
responding percentages for the comparison with aspirin in the VKA-unsuitable population are $95 \%$ and $98 \%$ (Figure 5 ).

The substantial stability of model results is further confirmed by the analysis of apixaban vs. warfarin conducted on the cohort reproducing the clinical features and demographics of the real world population described in [13]: mean incremental QALYs and costs are both estimated slightly lower ( 0.15 vs. 0.20 and 900 vs. $1100 €$, respectively), but the resulting ICER is comparable - about $6,200 € /$ QALY gained.

\section{CONCLUSIONS}

In NVAF patients unsuitable for VKA treatment, studied in the AVERROES trial, apixaban compared favourably with ASA, reducing the incidence of stroke or systemic embolism, without increasing the incidence of bleedings (ICH included). In the ARISTOTLE trial, apixaban was clearly superior to warfarin in preventing stroke or systemic embolisms, with a concomitant reduction in bleedings (including haemorrhagic stroke) and more importantly in all-cause mortality.
These data lead to very favourable pharmacoeconomic indicators, which suggest that the introduction of apixaban in the treatment of Italian NVAF patients represents an efficient allocation of health care resources, as compared to the treatment which are currently the standard of care. Furthermore, the calculated cost/effectiveness neglects an aspect which has the potential to increase the convenience of apixaban: it is the first and currently only NOAC to have demonstrated efficacy also in VKA-unsuitable patients, and will therefore be considered as relevant option by the decision makers in this specific subpopulation. This may avoid the discomfort, risk, and cost of treatment failures in patients who would otherwise be started on less specific treatments, or with warfarin, with the subsequent need for therapeutic revision, in case VKA-unsuitability should emerge.

In conclusion, the clinical data and expected pharmacoeconomic performance of apixaban is favourable, and it can be considered a welcome new entry in the therapeutic armamentarium at the disposal of the physician caring for NVAF patients in Italy.

\section{REFERENCE}

1. European Heart Rhythm Association, European Association for Cardio-Thoracic Surgery, Camm AJ, et al. Guidelines for the management of atrial fibrillation: the Task Force for the Management of Atrial Fibrillation of the European Society of Cardiology (ESC). Eur Heart J 2010; 31: 2369-429; http://dx.doi.org/10.1093/eurheartj/ehq278

2. Kannel WB, Benjamin EJ. Status of the epidemiology of atrial fibrillation. Med Clin North Am 2008; 92: 17-40; http://dx.doi.org/10.1016/j.mcna.2007.09.002

3. Wolf CD, Rudd AG. The Burden of Stroke White paper: Raising awareness of the global toll of stroke-related disability and death

4. Wolf PA, Abbott RD, Kannel WB. Atrial fibrillation as an independent risk factor for stroke: the Framingham Study. Stroke 1991; 22: 983-8; http://dx.doi.org/10.1161/01.STR.22.8.983

5. Lamassa M, Di Carlo A, Pracucci G, et al. Characteristics, outcome, and care of stroke associated with atrial fibrillation in Europe: data from a multicenter multinational hospital-based registry (The European Community Stroke Project). Stroke 2001; 32: 392-8; http://dx.doi.org/10.1161/01.STR.32.2.392

6. Sacchetti MA, Spandonaro F, Finzi G, et al. Prevenzione dell'ictus in Italia - diversità regionali ed assetti. Sole 24 Ore sanità Allegato al n.10 del 15-21 Marzo 2011

7. National Institute for Health and Care Excellence. Atrial fibrillation: the management of atrial fibrillation. NICE Clinical guideline 36. NHS, 2006

8. Granger CB, Alexander JH, McMurray JJ, et al. Apixaban versus warfarin in patients with atrial fibrillation. $N$ Engl J Med 2011; 365: 981-92; http://dx.doi.org/10.1056/NEJMoa1107039

9. Connolly S, Eikelboom J, Joyner C, et al. Apixaban in patients with atrial fibrillation. $N$ Engl J Med 2011; 364: 806-17; http://dx.doi.org/10.1056/NEJMoa1007432

10. AIFA. Piano Terapeutico Eliquis ${ }^{\circledR}$ (apixaban)

11. Dorian P, Kongnakorn T, Phatak H, et al. Cost-effectiveness of apixaban vs. current standard of care for stroke prevention in patients with atrial Fibrillation. Eur Heart J 2014; 35: 1897-906; http://dx.doi.org/10.1093/eurheartj/ ehu006

12. Lip GYH, Kongnakorn T, Phatak H, et al. Cost-Effectiveness of Apixaban Versus Other New Oral Anticoagulants for Stroke Prevention in Atrial Fibrillation. Clin Ther 2014; 36: 192-210; http://dx.doi.org/10.1016/j.clinthera.2013.12.011 
13. Olesen JB, Lip GY, Hansen ML, et al. Validation of risk stratification schemes for predicting stroke and thromboembolism in patients with atrial fibrillation: nationwide cohort study. BMJ 2011; 342: d124; http://dx.doi.org/10.1136/ bmj.d124

14. [No author listed]. Risk factors for stroke and efficacy of antithrombotic therapy in atrial fibrillation. Analysis of pooled data from five randomized controlled trials. Arch Intern Med 1994; 154: 1449-57; http://dx.doi.org/10.1001/ archinte.1994.00420130036007

15. Ariesen M, Claus S, Rinkel G, et al. Risk factors for intracerebral hemorrhage in the general population: a systematic review. Stroke 2003; 34: 2060-5; http://dx.doi.org/10.1161/01.STR.0000080678.09344.8D

16. Mohan KM, Crichton SL, Grieve AP, et al. Frequency and predictors for the risk of stroke recurrence up to 10 years after stroke: the South London Stroke Register. J Neurol Neurosurg Psychiatry 2009; 80: 1012-8; http://dx.doi. org/10.1136/jnnp.2008.170456

17. Freeman JV, Zhu RP, Owens DK, et al. Cost-effectiveness of dabigatran compared with warfarin for stroke prevention in atrial fibrillation. Ann Intern Med 2011; 154: 1-11; http://dx.doi.org/10.7326/0003-4819-154-1-201101040-00289

18. Scarborough P, Bhatnagar P. Coronary Heart Disease statistics 2010 edition; British Health Foundation Health Promotion research group, Department of Public Health, University of Oxford

19. ISTAT. Available at: www.ISTAT.it (last accessed February 2014)

20. Friberg L, Hammar N, Pettersson H, et al. Increased mortality in paroxysmal atrial fibrillation: report from the Stockholm Cohort-Study of Atrial Fibrillation (SCAF). Eur Heart J 2007; 28: 2346-53; http://dx.doi.org/10.1093/ eurheartj/ehm308

21. Brønnum-Hansen H, Davidsen M, Thorvaldsen P. Long-Term Survival and Causes of Death After Stroke. Stroke 2001; 32: 2131-6; http://dx.doi.org/10.1161/hs0901.094253

22. Henriksson K, Farahmand B, Johansson S, et al. Survival after stroke - The impact of CHADS 2 score and AF. Int J Cardiol 2010; 141: 18-23; http://dx.doi.org/10.1016/j.ijcard.2008.11.122

23. Huybrechts K, Caro J, Xenakis J. The prognostic value of the modified rankin scale score for long-term survival after first-ever stroke. Cerebrovasc Dis 2008; 26: 381-7; http://dx.doi.org/10.1159/000151678

24. Brønnum-Hansen H, Jorgensen T, Davidsen M, et al. Survival and cause of death after myocardial infarction: the Danish MONICA study. J Clin Epidemiol 2001; 54: 1244-50; http://dx.doi.org/10.1016/S0895-4356(01)00405-X

25. Sullivan PW, Slejko JF, Sculpher MJ, et al. Catalogue of EQ-5D scores for the United Kingdom. Med Decis Making 2011; 31: 800-4; http://dx.doi.org/10.1177/0272989X11401031

26. Gage BF, Cardinalli AB, Owens DK. The effect of stroke and stroke prophylaxis with aspirin or warfarin on quality of life. Arch Intern Med 1996; 156: 1829-36

27. Informatore Farmaceutico on-line. Available at: http://www.codifa.it/ (last accessed February 2014)

28. Lucioni C, Garancini MP, Massi-Benedetti M, et al. The costs of type 2 diabetes mellitus in Italy: a CODE-2 sub-study. Treat Endocrinol 2003; 2: 121-33; http://dx.doi.org/10.2165/00024677-200302020-00005

29. Pengo V, Crippa L, Falanga A, et. al; Questions and answers on the use of dabigatran and perpectives on the use of other new oral anticoagulants in patients with atrial fibrillation: A consensus document of the Italian Federation of Thrombosis Centers (FCSA). Thromb Haemost 2011; 106: 868-76; http://dx.doi.org/10.1160/TH11-05-0358

30. Mennini FS, Russo S, Marcellusi A. Budget impact analysis resulting from the use of dabigatran etexilate in preventing stroke in patients with non-valvular atrial fibrillation in Italy. Farmeconomia. Health economics and therapeutic pathways 2012; 13: 121-31; http://dx.doi.org/10.7175/fe.v13i3.268

31. Fattore G, Torbica A, Susi A, et al. The social and economic burden of stroke survivors in Italy: a prospective, incidence-based, multi-centre cost of illness study. BMC Neurology 2012; 12: 137; http://dx.doi.org/10.1186/14712377-12-137

32. Remunerazione prestazioni di assistenza ospedaliera per acuti, assistenza ospedaliera di riabilitazione e di lungodegenza post acuzie e di assistenza specialistica ambulatoriale. DM 10/2012 on Gazzetta Ufficiale n. 23 of 1/28/2013

33. Mantovani LG, Fornari C, Madotto F, et al. Burden of acute myocardial infarction. Int J Cardiol 2011; 150: 111-2; http://dx.doi.org/10.1016/j.ijcard.2011.04.030

34. Colombo GL, Caruggi M, Vinci M, et al. Costo sociale annuo della dispepsia funzionale dopo l'eradicazione dell'Helicobacter pylori. PharmacoEconomics - Italian Research Articles 2005; 7: 27-42; http://dx.doi.org/10.1007/ BF03320533 